\title{
Milk-derived supplement inhibits in vitro lymphocyte proliferation and IL-2 production
}

\author{
S. Marín-Gallén, F. J. Pérez-Cano, M. Castell, C. Castellote and A. Franch \\ Department of Physiology, Faculty of Pharmacy, University of Barcelona, Barcelona, Spain
}

Recently, significant progress has been made in the characterisation of milk components affecting the function of the immune system. The aim of the present report was to study the effect of a premium ultra-grade freeze-dried bovine whey-protein concentrate (WPC) on the functional capacity of lymphocytes. Thus, the immunomodulating properties of this dairy extract were evaluated in relation to the proliferative response of spleen $\mathrm{T}$ and B lymphocytes. Splenocytes from adult Wistar rats were incubated in a medium supplemented with WPC $(60-480 \mu \mathrm{g}$ protein $/ \mathrm{ml})$, which contains $(\mathrm{g} / \mathrm{kg})<0.1$ fat, $750-900$ proteins and $35-50$ carbohydrates, and also lactoferrin $9.2 ;$ IgG 300-600, IgA 50-70 and IgM 70-90 and high proportions of active compounds, e.g. natural growth factors and hormones, vitamins and amino acids. Standard commercial infant formula (SIF; $40-415 \mu \mathrm{g}$ protein/ml) and BSA (250-500 $\mu \mathrm{g}$ protein/ml) were also added as milkderived and inert control proteins respectively. Concanavalin A (ConA; specific stimulus for T-cells) or pokeweed (Phytolacca americana) mitogen (specific for B-cells) were added to the cell culture for $72 \mathrm{~h}$. Proliferating cells were quantified by means of the BioTrak ${ }^{\mathrm{TM}}$ cell proliferation system (BioTrak, Carlsbad, CA, USA) based on 5-bromo-2'-deoxyuridine incorporation. IL-2 levels were quantified by ELISA in $24 \mathrm{~h}$-culture supernatant fractions obtained from ConA-stimulated lymphocytes. Statistical analysis was performed by conventional ANOVA and when an experimental group variable had a significant effect on the dependent variable post hoc comparisons (LSD test) were performed. Significant differences were accepted at $P<0.05$.

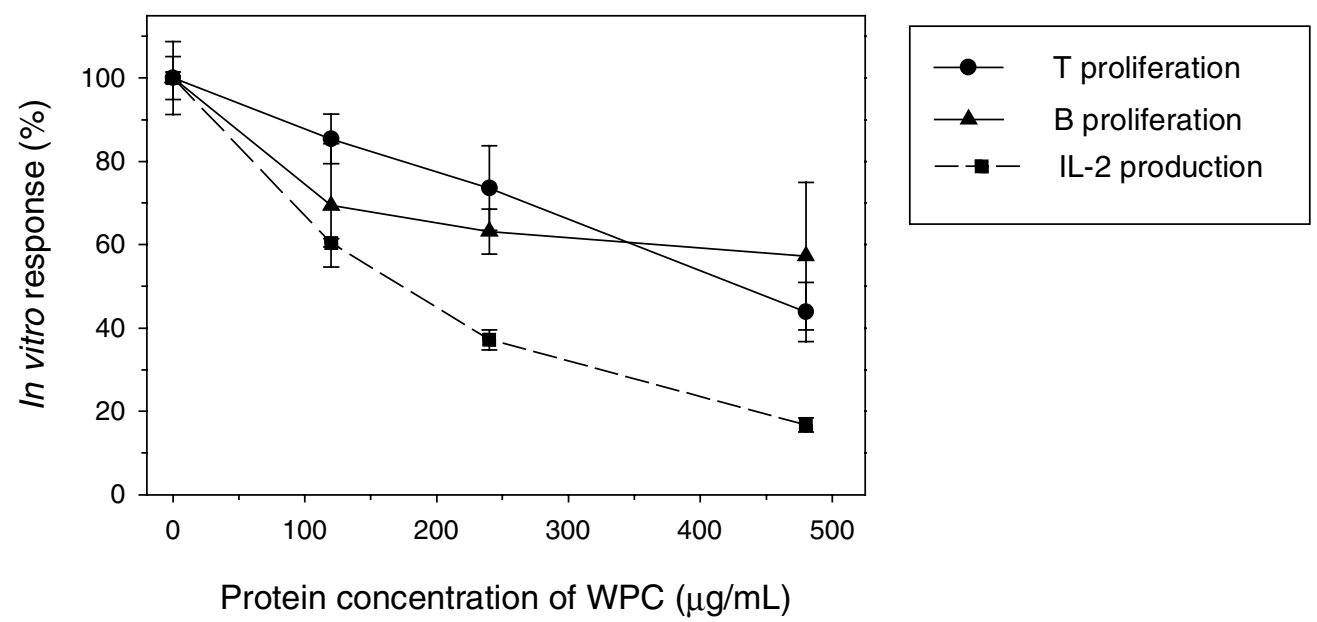

Results showed a dose-dependent inhibitory effect of WPC on both spleen B- and T-lymphocyte proliferative response induced by mitogen stimulation (see Figure). The inhibitory effect on T- and B-cell proliferation was approximately 55\% and approximately $40 \%$ respectively. In parallel, a WPC dose-dependent inhibition of IL-2 production was also found (approximately $80 \%$ ). Cell viability was not modified by WPC addition. SIF produced similar inhibitory effects. However, non-milk-derived proteins such as BSA did not modify these lymphocyte responses. WPC and SIF, both milk-derived components, inhibited lymphocyte proliferation and IL-2 production in vitro. This immunomodulatory effect may prevent the newborn from over-reacting immunologically to the environmental antigens during early life. 